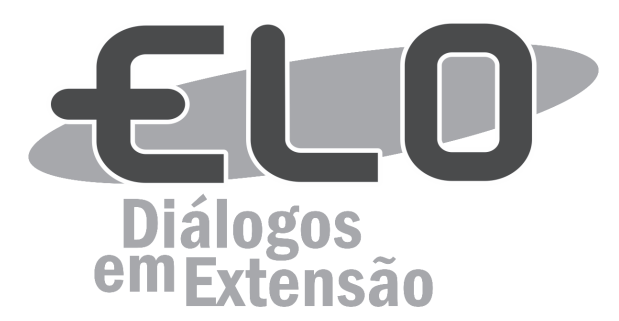

\title{
O REVELAR DAS "VOZES DA BOCA DA MATA": a experiência da extensão universitária nos assentamentos de reforma agrária em Nossa Senhora da Glória- SE
}

Claudia Kathyuscia Bispo de Jesus ${ }^{1}$

\begin{abstract}
Resumo: Este trabalho é fruto de uma atividade de Iniciação à Extensão (PIBIX) da Universidade Federal de Sergipe (UFS). O trabalho alicerçou-se metodologicamente na pesquisa-ação, possuindo como foco a questão dos direitos sociais e, especialmente, a categoria qualidade de vida em seis assentamentos rurais localizados no município de Nossa Senhora da Glória, no Sertão Sergipano. O método utilizado concentrou-se no uso de grupos focais. Em suma, este trabalho permitiu, além de pesquisar as famílias assentadas e permitir que elas pudessem se apropriar e construir reivindicações/demandas voltadas para os direitos sociais e a qualidade de vida nos seus assentamentos, revelar vozes, até então, ocultas, contribuindo assim na compreensão de como elas vivenciam suas conquistas sociais, entendem e experienciam suas vidas.
\end{abstract}

Palavras-chave: Famílias rurais assentadas. Direitos sociais. Qualidade de vida.

Área Temática: Direitos Humanos e Justiça.

\section{THE REVEAL THE "VOICES OF MATA OF MOUTH": the experience of university extension} in the agrarian reform settlements in Our Lady of Glory-SE

\begin{abstract}
This work is the result of a Start activity to the extension (PIBIX) of the Federal University of Sergipe (UFS). Our project was methodologically its foundations in action research, having focused on the issue of social rights and especially the quality of life category in six rural settlements in the municipality of Nossa Senhora da Gloria, in the Hinterland Sergipe. The method focused on type of use of focus groups. In short, this work allowed, in addition to research and contribute to settled families could take ownership and build claims / demands facing social rights and the quality of life in their settlements, revealing voices hitherto hidden, thus contributing to the understanding how they experience their social achievements, they understand and experience their lives.
\end{abstract}

Keywords: Seated rural households. Social rights. Quality of life.

\section{El revelar la "VOCES DE MATA DE BOCA": la experiencia de extensión universitaria en los asentamientos de la reforma agraria en Nuestra Señora de la Gloria- SE}

Resumen: Este trabajo es el resultado de una actividad de inicio de la extensión (PIBIX) de la Universidad Federal de Sergipe (UFS). La obra tiene sus fundamentos metodológicos de la investigación-acción, al haber centrado en el tema de los derechos sociales y sobre todo la calidad de la categoría de la vida en seis asentamientos rurales en el municipio de Nossa Senhora da Glória, en el Hinterland Sergipe. El método se centró en el tipo de uso de grupos de enfoque. En resumen, este trabajo permitió, además de la investigación y contribuir a familias asentadas podrían apropiarse y construir reclamos / demandas que enfrentan los derechos sociales y la calidad de vida en sus asentamientos, revelando voces hasta entonces ocultos, lo que contribuye a la comprensión cómo experimentan sus logros sociales, entienden y experimentan sus vidas.

Palabras clave: Asentado familias rurales. Los derechos sociales. Calidad de vida.

${ }^{1}$ Professora substituta da Universidade Estadual da Paraíba (UEPB). Mestre em Sociologia pela Universidade Federal de Sergipe (UFS). Rua Baraúnas, 351 - Bairro Universitário - Campina Grande-PB, CEP 58429-500, Fone/Fax: 83 3315.3300. Email: claudia_kathyuscia@hotmail.com 


\section{Introdução}

Este trabalho é fruto de um conjunto de atividades realizadas no âmbito do programa institucional de Bolsas de Iniciação à Extensão (PIBIX) da Universidade Federal de Sergipe (UFS). O nosso projeto alicerçou-se metodologicamente na pesquisa-ação, possuindo como foco a questão dos direitos sociais e, especialmente, a categoria qualidade de vida em seis assentamentos rurais localizados no município de Nossa Senhora da Glória, no Sertão Sergipano.

Nossa Senhora da Glória (ou antiga "Boca da Mata", em sua primeira povoação) é conhecida como a "Capital do Sertão" e caracteriza-se por ser um polo regional, particularmente em função da força de sua bacia leiteira. Tem uma área de $756,485 \mathrm{~km}^{2}$, onde, segundo o último Censo do IBGE, vivem 32.497 habitantes, sendo que mais de 11.000 moram nas áreas rurais. O município está localizado ao oeste de Sergipe, situado a $122 \mathrm{~km}$ de distância de $122 \mathrm{~km}$ de Aracaju e integra o território do Alto Sertão Sergipano. Os sujeitos da pesquisa foram as famílias dos assentamentos de reforma agrária do município de Nossa Senhora da Glória- SE, a saber: Zé Emídio (25 famílias); Zé Ribamar (32 famílias); Luiz Beltrane (20 famílias); Fortaleza (o primeiro desta região, com 46 famílias) e, por fim, o mais recente, o Adão Preto (100 famílias). Para tanto, durante o desenvolvimento deste trabalho (de 8/ 2011 a 8/2012), realizamos a dinâmica metodológica (que será aprofundada mais adiante) em 6 (seis) assentamentos rurais.

\section{O camponês e seu protagonismo}

A história do campesinato brasileiro é registrada pelas marcas de suas lutas na obtenção de um espaço próprio na economia e na sociedade, de processos sociais de resistência pelo direito de existir, enquanto homens e mulheres, em termos políticos, sociais, culturais e econômicos (WANDERLEY, 2009). O campesinato no Brasil sempre foi um setor bloqueado historicamente, especialmente por conta da negação sistemática, em diversas localidades, do acesso dessa população a terra (WANDERLEY, 2009). De tal modo, a questão da luta por espaço, a ideia de construção de um território ${ }^{2}$ aponta, por si só, para o protagonismo do camponês, na qualidade de que este foi capaz de edificar - mesmo em situações profundamente adversas - um lugar tecido por seu modo de vida, suas formas de sociabilidade, experiências e lutas políticas, processos de produção e reprodução da vida.

Questões mais gerais - do ponto de vista político, principalmente colocaram na ordem do dia o tema do campesinato. Por decorrência do processo de internacionalização da indústria brasileira, bem como do avanço do capitalismo no campo, que impulsionaram o desenvolvimento da modernização do processo produtivo na agricultura, desencadeou-se, enquanto reação a essa modernização excludente, uma forte organização dos trabalhadores rurais em vários municípios no País, que repercutiu em âmbito nacional por conta de seus atos políticos na década de 1950 e, principalmente, nos primeiros anos da década de 1960, que antecederam à implantação do Regime Militar em 1964. A organização política dos camponeses contou com o apoio dos partidos políticos, sobretudo do Partido Comunista Brasileiro (PCB) e da Igreja Católica, os quais reunidos no I Congresso Nacional dos Lavradores e Trabalhadores Agrícolas, em 1961, formularam, pela primeira vez, uma proposta unitária de reforma agrária brasileira, como síntese de suas interpretações políticas acerca da questão agrária no país, gerando repercussão na imprensa (rádio e jornal, na época). Destarte, "essas eram as condições em que estava ocorrendo à redefinição política das relações de classes no campo. Isto é, pouco a pouco, verificava-se a metamorfose política do lavrador em camponês" (IANNI, 2004, p. 212), especialmente na condição de elaboração de sua identidade política.

A agenda política desses grupos campesinos expressava questões como: (a) reforma agrária; (b) livre direito à organização sociopolítica da classe trabalhadora rural; (c) extensão de direitos trabalhistas para o campo, bem como previdenciários; e (d) políticas públicas ligadas ao desenvolvimento produtivo no campo, fundamentalmente para a pequena produção rural (ANDRADE 2005; MARTINS, 1983). O elenco de aspectos aludidos acima mostra como as áreas rurais estavam incólumes aos direitos de cidadania, por causa, principalmente,do poder das elites agrárias em negá-los constantemente ${ }^{3}$. Vale frisar que, esse período efervescente permitiu o acirramento dos conflitos no campo entre fazendeiros e camponeses, sobretudo, com a criação e a ação das Ligas Camponesas ${ }^{4}$. 
Em meio à retomada das manifestações populares no período decisivo de encerramento do regime militar, o movimento camponês ganhou (novo) impulso, com destaque para o Movimento dos Trabalhadores Sem Terra (MST) 5 . De acordo com Stédile e Fernandes (2012), as raízes do surgimento desse movimento foram determinadas por diversos fatores, dentre os principais: a) o aspecto socioeconômico das transformações que a agricultura brasileira sofreu na década de $70 ; b$ ) modernização e industrialização no campo; c) a era da colonização da região Norte do país. Portanto, o nascimento do MST tem suas raízes nas condições objetivas do desenvolvimento da agricultura, logo, “O MST não surgiu só da vontade do camponês. Ele só pode se constituir como um movimento social importante porque coincidiu com um processo mais amplo de luta pela democratização do país" (STÉDILE; FERNANDES, 2012, p. 24).

Sônia Bergamasco (1996) define os assentamentos como a criação de novas unidades de produção agrícola, de base familiar, por meio de políticas governamentais, visando o (re)ordenamento do uso da terra, em benefício de trabalhadores rurais sem terra ou com pouca terra. Além disso, possibilitou o incentivo à organização social e a vida comunitária; os laços de sociabilidade tradicionais do campo, onde o parentesco e a vizinhança assumem papel preponderante.

No que se refere à família rural no projeto de reforma agrária, a mesma acaba assumindo caráter central, pois a criação dos assentamentos é a validação da importância e reconhecimento da família como elemento fundamental para a vida nos assentamentos, já que, "o sujeito da conquista do assentamento de reforma agrária tem um núcleo basicamente familiar, e de família extensa" (MARTINS, 2002, p. 19). Segundo Schneider (2003), a família rural é entendida como um grupo social que compartilha um mesmo espaço, possui em comum a propriedade de um pedaço de terra para cultivo agrícola e está ligada por laços de parentesco e consanguinidade (filiação), podendo, ainda, pertencer a ela outros membros não consanguíneos (adoção, compadres).

Diante dessa conceituação, parte-se da ideia de que a família rural assentada tenta garantir a reprodução social do grupo familiar e, consequentemente, a melhoria das condições de vida. Por isso, ela (a família rural) é a base de nossa compreensão e das nossas respostas acerca da questão da busca pela implementação dos direitos sociais em seus respectivos assentamentos rurais de reforma agrária. São essas famílias e as dinâmicas existentes nos assentamentos que têm possibilitado em vários municípios formas de inclusão social antes precarizadas pela ausência da posse da terra. Ademais, são elas que passam a buscar qualificar as políticas dos poderes públicos municipais, cobrando escolas, postos de saúde, melhorias de infraestrutura (BERGAMASCO, 2003; MARTINS, 2004).

\section{A bandeira dos Direitos Sociais e da Qualidade de Vida}

A partir do pressuposto que as famílias rurais assentadas são as protagonistas na busca por melhores condições de vida nos assentamentos e que desenvolvem, em muitas localidades, modos de cobranças para garantir uma maior e melhor aplicação de políticas públicas no meio rural, foram elas que se tornaram alvo de nosso trabalho ${ }^{6}$.

É importante destacar que, direitos são "a expressão de um patamar de sociabilidade e estão situados em um campo essencialmente político, porque são resultantes do embate de interesses e ações dos sujeitos sociais" (IAMAMOTO, 2004, p. 20). Desse modo, pressupõem as ideias de igualdade e justiça a partir da compreensão das desigualdades sociais vigentes na sociedade capitalista. Assim, a nossa compreensão pelo termo direito social parte do entendimento de que direitos são resultados de processos reivindicatórios ao longo do tempo; portanto, falar em direitos sociais significa mencionar os processos históricos de participação e reivindicação popular.

Partindo para uma procura histórica da inserção da sociedade civil no processo de participação junto aos poderes públicos, percebe-se que, nas décadas de 1980 e 90, fundamentalmente resultante do período de redemocratização brasileira, inúmeros debates emergiram na sociedade brasileira, bem como relevantes produções teóricas que foram surgindo com o intuito de contextualizar não só os paradigmas da participação da sociedade civil, mas também nas caracterizações dos seus diferentes campos de atuação. No Brasil, tal processo deu-se em uma conjuntura de emergência da democracia, da luta por direitos sociais, pós o fim da ditadura militar na década de 1980. Assim, o processo de participação da sociedade civil como direito, no que refere ao controle dos direcionamentos das políticas públicas, como também de sua presença nos programas sociais emergiu em um contexto sociopolítico de redemocratização da sociedade brasileira (MARTORANO, 2010). 
A palavra participação historicamente foi associada a outros termos como democracia, representação, organização, cidadania. Compreendemos o termo participação neste trabalho enquanto um nível político de integração social de indivíduos em dados grupos (GOHN, 2003). Neste viés, percebese a participação do MST em Conselhos ${ }^{7}$.

Em sentido amplo, os conselhos são "canais de participação que articulam representantes da população e membros do poder público estatal em práticas que dizem respeito à gestão de bens públicos". (GOHN, 2003, p.7). Desse modo, os Conselhos Gestores surgiram em todo o país nos anos de 1990 em cumprimento às leis orgânicas que regulamentaram a Constituição Federal de 1988. Tais dispositivos legais resultaram de um processo histórico de lutas e reivindicações da sociedade civil organizada, ocorridas no contexto dos anos 1970 e 1980, enquanto expressão da crise da ditadura militar implantada desde 1964. Os movimentos sociais, sindicatos, associações de profissionais, de bairro, dentre tantas, contestavam a centralização do poder e exigiam a democratização do Estado, com participação da sociedade civil nas decisões sobre as políticas públicas, num amplo movimento pela redemocratização do país, fato que culminou com o fim do regime militar em 1985 após 21 anos de ditadura ${ }^{9}$ (GOHN, 2003).

No universo da política, a participação dos indivíduos na sociedade civil tornou-se parte do vocabulário não só dos dicionários da ciência política, mas também nos "gritos de ordem" das reivindicações populares. A integração dos indivíduos nos processos de elaboração e tomadas de decisão, além do controle sobre os recursos e as instituições que controlavam o "andamento do social" na sociedade, emergiu fortemente nos anos de 1980 no Brasil, onde intensificou a necessidade de criação de mecanismos que garantissem uma maior participação dos segmentos organizados da sociedade civil (por exemplo, representações comunitárias e profissionais, sindicatos, movimentos populares).

Assim, um desses principais canais, ao menos teoricamente, era a possibilidade de criação de Conselhos, que oferecesse não apenas um instrumento de pressão das demandas populares, mas também uma qualidade da participação, aspecto que se apresentou de modo generalizado - não somente - para vários municípios rurais (GOHN, 2003). Os conselhos foram criados com a finalidade de diálogos entre o espaço público e os setores da sociedade civil, especialmente as camadas populares, voltado para demandas sociais (educação, saúde, renda, desenvolvimento sustentável, etc.).

No que diz respeito às demandas populares por melhorias na qualidade de vida, a nossa abordagem se respaldou, ademais, na definição proposta por Metzen; et al (1980), para qual a avaliação da qualidade de vida envolve indicadores que estão associados tanto aos aspectos objetivos (informações sobre as condições concretas e gerais da vida das famílias e do seu habitat), quanto a fatores subjetivos (relacionados às percepções, avaliações e aspirações que as pessoas/família têm de suas próprias condições) ${ }^{10}$.

Desta forma, o presente trabalho de extensão almejou levar essa discussão para dentro desses assentamentos por meio de grupos focais, oferecendo possibilidades para que os assentados (as) se apropriem dos marcos legais do II- Plano Nacional de Reforma Agrária (PNRA) ${ }^{11}$, corroborando com as demandas relativas ao tema da qualidade de vida. A ideia era que as famílias e sua instância de representação política (a associação) passem a exigir, nos respectivos Conselhos Gestores existentes no seu município, que tais aspectos (direitos sociais e qualidade de vida) sejam incorporados pelas políticas públicas e pela ação dos agentes da Assistência Técnica Rural (ATER/ ATES ${ }^{12}$ ). Nesse sentido, as famílias assentadas são protagonistas da reforma agrária e é sobre elas que devem se situar um conjunto de iniciativas capazes de possibilitar a consolidação e/ou a intensificação da luta pela conquista de direitos sociais e pela melhoria na qualidade de vida, uma vez que a posse da terra ainda não assegura a plena garantia de condições de permanência por intermédio do acesso a bens e serviços essenciais ao indivíduo na manutenção do seu núcleo familiar.

\section{Percurso metodológico}

Esse trabalho alicerçou-se metodologicamente na pesquisa-ação em seis assentamentos rurais localizados no município de Nossa Senhora da Glória, no Sertão Sergipano, com público-alvo de 242 famílias assentadas na região do Alto Sertão Sergipano. A técnica de coleta de dados foi à realização de grupos focais ${ }^{13}$, que, além de discutir e aprofundar os temas citados, também fez um observatório ${ }^{14}$ 
direto e participante dos processos interacionais que emergiram durante o grupo focal. A realidade focalizada e trabalhada foi a das famílias rurais dos assentamentos do município de Nossa Senhora da Glória, representando um total de 6 (seis) assentamentos.

O método pesquisa-ação ${ }^{15}$ busca interligar conhecimento e ação. $O$ método ainda é de relevante utilização nas ciências sociais aplicadas em atividades de extensão universitária, sempre associado não apenas aos objetivos de ação, mas também a pesquisa de novos conhecimentos respaldados em marcos teóricos. Nesse viés, a aplicação dessa metodologia e de sua técnica de coleta de dados possibilitou fazermos um levantamento qualitativo a respeito do que as famílias rurais assentadas pensam sobre: a) a reforma agrária enquanto um direito social; b) se as mesmas conhecem e/ou tem contato com os conselhos gestores existentes no seu município; c) o que elas entendem por qualidade de vida.

Nesse sentido, buscamos ouvir os assentados de reforma agrária e saber por eles e elas quais são seus conhecimentos de acesso aos (seus) direitos sociais. Portanto, tivemos um cuidadoso exercício de saber ouvir essas vozes, até então, ocultas, vozes essas não reveladas nos dados estatísticos oficiais. É nessa perspectiva que o nosso trabalho buscou ter potencial criativo, uma vez que, ao desfrutar de técnicas de pesquisa participante/qualitativas ${ }^{16}$, tivemos a possibilidade de realizar uma colheita expressiva de informações das condições em que se encontra (os assentamentos de reforma agrária do município de Nossa Senhora da Glória) no acesso aos mecanismos de ingresso às políticas públicas e nos Conselhos Gestores, principalmente tendo como base os resultados de nossas discussões com as famílias campesinas.

\section{Resultado}

No tocante à qualidade de vida, bem como à compreensão da reforma agrária enquanto um direito social, foi unânime a percepção entre os participantes dos grupos focais. Abaixo descrevemos alguns momentos do diálogo:

[facilitador]: "O que é ser assentado?".

[participantes]: "conquista do direito a terra";

[participantes]: "considerar cidadão";

[participantes]: "direito de plantar";

[participantes]: "a liberdade";

[participantes]: "ter uma terrinha... é o começo de cada um... a mudança para o trabalho coletivo";

Após as dinâmicas de reflexões, lançada no grupo focal, pôde-se perceber a satisfação dos assentados rurais com a conquista da terra havia alguns acampamentos com mais de dez anos de espera. Entretanto, eles reconheciam que somente a obtenção do lote não garantia a qualidade de vida, pois isso dependia do acesso às condições básicas.

As expectativas para o futuro enlaçam elementos que vão da conquista da casa e de condições de crédito para o trabalho - aquilo que, no entender de Wanderley (2004), é articular o ideal camponês, o de morar e trabalhar em sua terra -, que se combinam a necessidade de escola para os filhos, água, saneamento. Esses componentes - entes da representação deles sobre qualidade de vida - passam, sem dúvida alguma, pela conquista dos direitos sociais, ou seja, um depende de modo contundente do outro.

Sobre as percepções dos conselhos existentes no município de Nossa Senhora da Glória, por parte das famílias rurais assentadas, ver gráfico a seguir.

Percebe-se que, no gráfico 1, os conselhos mais conhecidos (conhecido no sentido de saber de sua existência e de, às vezes, os conselheiros fazerem visitas às famílias nos assentamentos) por parte das famílias assentadas que participaram dos grupos focais foram: o Conselho Municipal de Assistência Social (CMAS); o Conselho Municipal de Desenvolvimento Sustentável (CMDS); e o Conselho Municipal de Saúde (CMS).

Serão sobre os três aludidos conselhos que teceremos alguns comentários. Primeiro, a respeito do CMAS, foi unânime o conhecimento do mesmo por parte dos assentados, visto que é esse conselho o responsável pela aplicação dos principais programas de assistência do governo federal, a exemplo do benefício Bolsa Família; Programa Pró-jovem e o Programa de Erradicação do Trabalho Infantil (PETI). Esse conselho é paritário e composto por 10 membros titulares e os respectivos suplentes. 


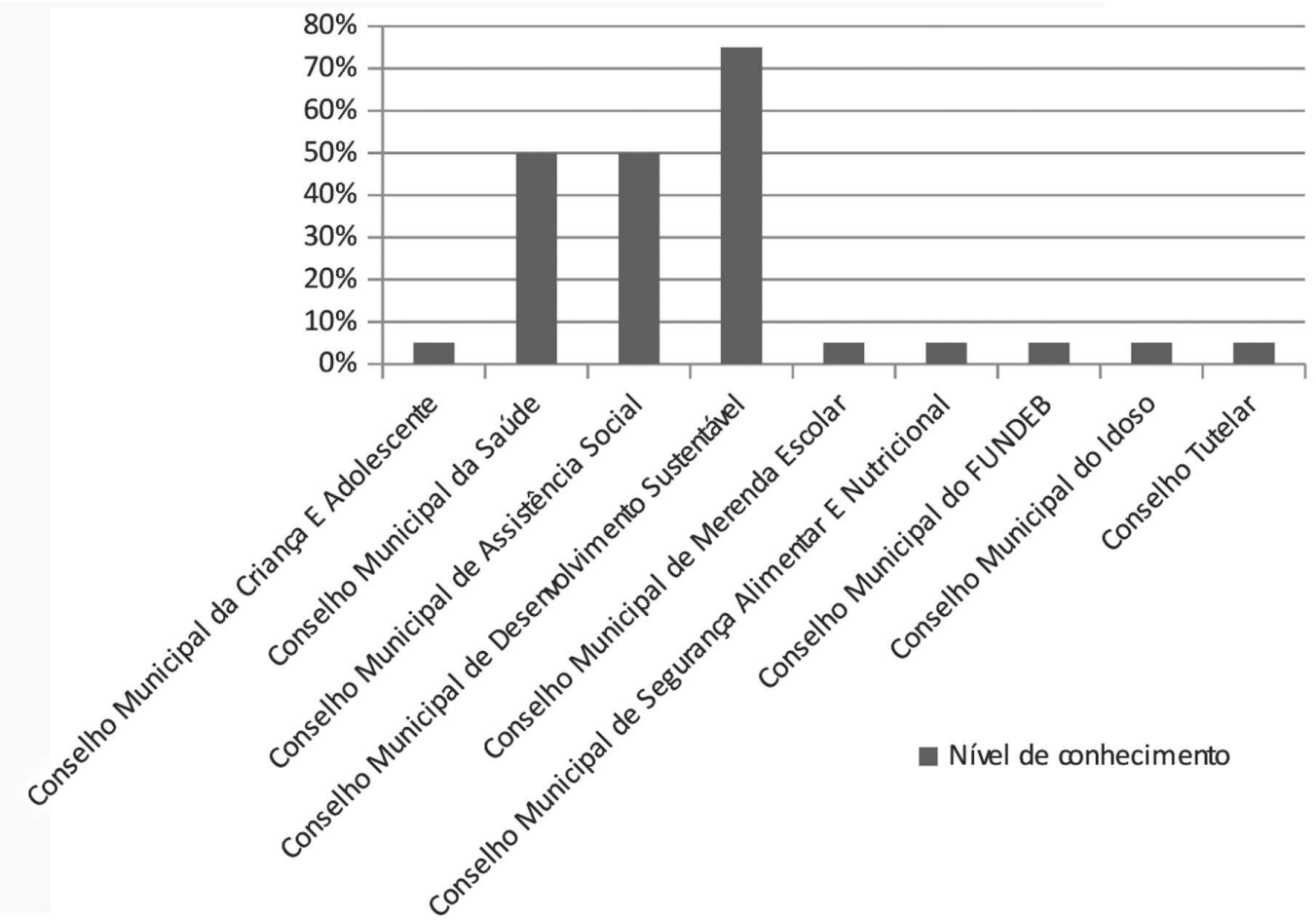

Fonte: dados da pesquisa de campo (2012)

O CMDS é composto por 15 membros, sendo que $80 \%$ representam a sociedade civil e $20 \%$ é composto por representação governamental. De acordo com os relatos dos participantes nos grupos focais, esse conselho desempenha um papel importante nos assentamentos de reforma agrária, pois é por meio dele que o assentado tem acesso às linhas de crédito, incentivo agrícola para a sua produção e também aos programas de apoio do governo ao pequeno agricultor, como é o Auxílio Safra e, recentemente, o Bolsa Estiagem. Em suma, O Conselho de Desenvolvimento Sustentável é um dos conselhos que tem um histórico de participação de movimentos sociais do campo (em especial o MST), zois se qaragteriza cemo principal canalde acesso às políticas agrícolas de producãa (RIBEIRO \&

No decorrer da pesquisa-ação percebemos que, dos seis assentamentos trabalhados, três tinham representantes em tal conselho (assentamento Adão Preto, Luís Beltrame e Zé Emídio, esse último tem dois conselheiros) o que chamou a atenção. Esses dados demonstraram que o Movimento dos Sem Terra-MST começa a perceber a importante estratégica de sua atuação dentro dos conselhos gestores, como uma garantia de reivindicação e de acesso aos direitos sociais. Logo, a participação e o controle social, por esse grupo no Conselho de Desenvolvimento Sustentável são de valiosa contribuição para a manutenção da produção do assentamento, bem como da garantia de permanência das famílias assentadas ${ }^{17}$.

Portanto, a participação de militantes do MST nesses arranjos institucionais é uma tentativa de obtenção de recursos públicos para as famílias assentadas, haja vista que, após o processo de conquista da terra, inicia-se outra luta pela consolidação e manutenção dos assentamentos rurais de reforma agrária.

Ademais, pode-se mencionar que o Conselho Municipal de Saúde (CMS), vinculado a Secretaria Municipal de Saúde, tem como objetivo a promoção da saúde pública, bem como a capacitação dos seus respectivos conselheiros. No entanto, esse conselho foi citado por todos os participantes nos grupos focais de maneira satisfatória e insatisfatória. Satisfatória por ser um dos poucos que tinham representantes fazendo visitas domiciliares (visita médica móvel, contendo médico, agente de saúde e, às vezes, dentista). E insatisfação pelas dificuldades de marcação de exames nos postos de saúde, nas proximidades dos assentamentos.

Além disso, é importante destacar que é notável o não conhecimento, por parte dos assentados da existência e/ou ausência do Conselho de Segurança Alimentar e Nutricional e do Conselho do Idoso. Assim, uma indagação é necessária para melhor caracterizar essa problemática: i) Será que tais conselhos estão limitados às demandas da população urbana do município de Glória? ii) quais são as dificuldades 
desses conselhos de estenderem suas finalidades à zona rural do município? Essa última indagação pode ser feita aos demais conselhos supracitados (no gráfico 1), pois parece ser um dilema que envolve não somente os assentados do município, mas também as demais populações longínquas de conselhos gestores, ou seja, o sistemático abandono que o Estado brasileiro ofertou as populações rurais no País (MARTINS, 2006).

Esse cenário pode ser compreendido pelos dilemas do desmantelamento no Brasil, ocasionado pelo efeito das políticas neoliberais que alastra o agravamento das desigualdades e exclusões sociais e, consequentemente, a falência dos serviços públicos e a regressão de direitos civis (TELLES, 1999).

Por fim, pôde-se perceber que um conjunto de dificuldades - delegação de poderes, desconhecimento dos marcos legais das políticas públicas, altos índices de analfabetismo, necessidades imediatas de sobrevivência que precisam ser garantidas cotidianamente - acabam reproduzindo situações desfavoráveis de construção de ações políticas consistentes na busca de pressionar esses conselhos, além de outras instâncias governamentais (municipais, estadual e federal), para a conquista de direitos e de qualidade de vida mais digna.

\section{Considerações Finais}

É possível perceber que o surgimento do assentamento rural representou (e representa) uma tentativa de redemocratização do acesso às terras. Além disso, simbolizou (e simboliza) a materialização da jornada de lutas históricas pela terra ao longo do processo de colonização do Brasil. Ademais, a existência do Movimento dos Trabalhadores Sem Terra (MST), bem como de outros movimentos camponeses, no panorama político nacional colocam, na ordem do dia, reivindicações da garantia de permanência desses sujeitos na viabilização de sua reprodução social.

Assim, é perceptível a busca por novas formas de participação política, por parte do movimento, a exemplo da inserção e participação de assentados (as) rurais nos conselhos gestores, a fim de, nesses espaços, protagonizar (novas) lutas na obtenção de direitos sociais, consequentemente, garantindo uma melhoria nas suas condições de vida.

Vale ressaltar também que, vivemos uma época de destruição do legado das conquistas históricas dos trabalhadores, em detrimento dos interesses do capital sob sua ideologia neoliberal, com isso a presença do Estado Mínimo no regresso dos direitos. Mediante a essa conjuntura, que afeta não somente o meio rural, faz-se necessário resgatar o papel do Estado no processo de reforma agrária, como prevê o II- PNRA, que deve orientar-se na viabilização da promoção do acesso à terra, bem como o acesso a direitos referentes à seguridade social (saúde, previdência e assistência social), a fim de possibilitar a garantia da qualidade de vida no campo.

No decorrer do processo da atividade de extensão podem-se pontuar como considerações finais que foram apreendidas várias características dos modos de pensar e os níveis de percepção das condições de vida das famílias rurais assentadas do município de Nossa Senhora da Glória (antiga Boca da Mata). Desse modo, vale ressaltar a importância da extensão universitária não somente pela sua função social, mas também pela sua contribuição teórico-empírica emergida no decorrer do seu processo de aplicação e desenvolvimento, num eterno fazer-se no próprio ato do saber-fazer acadêmico. Assim, desmistifica-se a ideia de que a extensão universitária é 'assistencialismo', prestadora de serviço e que não se alicerça no fazer científico da produção do conhecimento (FREIRE, 2011).

No geral, o que foi levantando e trabalhado junto às áreas assentadas possibilitou a socialização (e levantamento) de informações sobre a situação da qualidade de vida desses assentamentos ilustrados por meio da análise de seus indicadores objetivos e isto se deu por intermédio da busca por saber do seu conhecimento e por acesso aos conselhos gestores, uma vez que esses são os canais de contato com os benefícios públicos; e de outro modo, pela compreensão dos fatores subjetivos, relacionados às percepções, avaliações e aspirações que as famílias assentadas têm de suas próprias condições ${ }^{18}$. Portanto, obtivemos a materialização do objetivo do nosso trabalho, que era o de buscar compreender como as famílias assentadas vivenciam suas conquistas sociais, entendem e experienciam a vida nos assentamentos.

Esses dados obtidos, ou melhor, essas "vozes ouvidas", não constam nos dados estatísticos oficiais. Uma vez que, na atualidade, as várias pesquisas realizadas em assentamentos rurais sobre as suas condições e qualidade de vida estão, em sua maioria, restritos ao recurso dos dados de indicadores quantitativos. Com isso, não se tem a devida preocupação com o que eles representam para estas famílias. 
Vale ressaltar que, a pesquisa de campo não deve ser invasiva, entretanto, não negamos a ocorrência da nossa intervenção para com as famílias rurais assentadas no decorrer da pesquisa, intervenção esta que possibilitou obter de viva voz respostas, depoimentos e narrativas. De tal modo, "a interferência interpretativa do pesquisador se dá no desvendamento das conexões entre o visível e o invisível, entre o que chega à consciência e o que se oculta na alienação própria da vida social." (Martins, 2011, p. 14). De tal modo, podemos concluir que o nosso trabalho permitiu, em certa medida, suprir esse desconhecimento das condições e modos de vivenciar suas vidas (agora) na condição de assentados (as) rurais. Portanto, conseguimos, minimamente, fazer com que se ouça de outra forma aquilo que, até então, estava sem ser ouvido: as famílias rurais assentadas.

\section{Referências}

ABRA. Revista da Associação Brasileira de Reforma Agrária - ABRA (Edições de 1971 a 2014). Disponível em: <http://www.abrareformaagraria.com.br>. Acesso em: 6 abr. 2016.

ANDRADE, Manuel Correia de. A terra e o homem no Nordeste: contribuições ao estudo da questão agrária no Nordeste. $7^{\text {a }}$ edição. São Paulo, Cortez, 2005.

BERGAMASCO, Sônia Maria Pessoa Pereira. O que são assentamentos rurais. São Paulo: Brasiliense, 1996.

BRANDÃO, Carlos Rodrigues (Org.). Pesquisa Participante. São Paulo: Editora Brasiliense, 1981.

BRETAS, P. F. F.; SARAIVA, L. A. S. Discursos e sentidos da participação popular em um centro de saúde de Belo Horizonte. Revista Eletrônica de Ciência Administrativa, v. 13, n. 2, p. 203-218, 2014.

DELGADO, Guilherme. Expansão e modernização do setor agropecuário no pós-guerra: um estudo da reflexão agrária. Scielo, 2011. Disponível em:<http:// www.scielo.br/pdf/v15n43a13.pdf>. Acesso em: 15 jul. 2014.

FERNANDES, Bernardo Mançano. MST: movimento dos trabalhadores rurais sem-terra, formação e territorialização em São Paulo. São Paulo: HUCITEC, 1996.

FREIRE, Paulo. Extensão ou Comunicação? 15º edição São Paulo: Paz e Terra, 2011.

GATTI, Bernardete Angelina. Grupo focal na pesquisa em ciências sociais e humanas. Brasília: Líber Livro Editora, 2005.

GOHN, Maria da Glória. Conselhos Gestores e Participação sociopolítica. $2^{a}$ ed. São Paulo: Cortez Editora, 2003.

IAMAMOTO, Marilda Vilela. Prefácio In: COUTO, Berenice Rojas. O direito social e a assistência social na sociedade brasileira: uma equação possível? São Paulo: editora Cortez, 2006.

IANNI, Octavio. Origens Agrárias do Estado Brasileiro. São Paulo: Brasilense, 2004.

JULIÃO, Franciso. O que são ligas camponesas? São Paulo: Brasiliense, 1962.

LAVILLE, Christian. A construção do saber: manual de metodologia da pesquisa em ciencias humanas. Tradução: Heloísa Monteiro e Francisco Settineri. Porto Alegre: Editora Artes Médicas Sul Ltda; Belo Horizonte: Ed. UFMG, 1999.

MARTINS, José de Souza (Org.). Introdução crítica à sociologia rural. São Paulo: Hucitec, 1986.

MARTORANO, Luciano Cavini. Conselhos e Democracia: em busca da socialização e da participação. São Paulo: Expressão Popular, 2011.

MEDEIROS, Leonildes Servólos de. Movimentos sociais no campo, lutas por direitos e reforma agrária na segunda metade do século XX. In: CARTER, Miguel. Combatendo a desigualdade social: o MST e a reforma agrária no Brasil. São Paulo: Editora UNESP, 2010.

Os camponeses e a política no Brasil: as lutas sociais. Petrópolis-RJ, 1981. 
O futuro da sociologia rural e sua contribuição para a qualidade de vida rural. In: Estudos Sociedade e Agricultura, n. 15, out/2004, p. 5-12.

A sociedade vista do abismo: novos estudos sobre exclusão, pobreza e classes sociais. Petrópolis: Vozes, 2008.

METZEN, E.; WILLIAMS, F.L; SHULL, J.; KEEF, D.R. Quality of life as affected by area of residence. I project description. Columbia: University Missoure, College of Agriculture, Agricultural Experiment Station, 1980. 112 p. (Research Bulletin, 1036)

TELLES, Vera da Silva. Direitos Sociais: afinal do que se trata? Belo Horizonte: Ed. UFMG, 1999.

THIOLLENT, Michel. Metodologia da pesquisa-ação. São Paulo: editora Cortez, 18a edição, 2011.

WANDERLEY, Maria N. B. O mundo rural como um espaço de vida. Porto Alegre: Editora da UFRGS, 2009.

"Morar e trabalhar": o ideal camponês dos assentados de Pitanga. In: MARTINS, José de Souza (Org.). Travessias: a vivência da reforma agrária nos assentamentos. Porto Alegre: Editora da UFRGS, 2004. p. 203-247.

\footnotetext{
${ }^{2}$ Território no sentido de ser algo além de um espaço físico, é aquele em que há também relações socioculturais, história de vida, pertencimentos diversos (FERNANDES, 1996).

${ }^{3}$ Vale ressaltar que, atualmente, essa realidade vem sendo modificada. Sobre isso, ler Delgado, 2011.

${ }^{4}$ As ligas camponesas foram um movimento de camponeses que teve seu início no ano de 1954 em Pernambuco e, posteriormente, na Paraíba, donde emergiram suas principais lideranças: Elizabeth Teixeira, João Pedro Teixeira, Francisco Julião e outros (as). As ligas existiram até 1964, sendo eliminadas, assim como as demais organizações de camponeses e trabalhadores rurais sindicalizados vinculados à esquerda. Tudo isso levou a um silenciamento da identidade política projetada a partir das ações e dos valores de mundo dos próprios homens do campo (JULIÃO, 1962).

${ }^{5}$ O Movimento dos Trabalhadores Sem Terra (MST) surgiu na região Centro-Sul do Brasil no período de 1984- 1985. O movimento só teve contorno e repercussão nacional a partir dos anos 90, em função das vitórias e emblemas dos processos de ocupações de terra da época, a exemplo da ocupação na fazenda Macali. (TURATTI, 2005).

${ }^{6}$ Como o presente texto resulta de um trabalho de extensão, o nosso objetivo é, além de pesquisar, contribuir para que famílias assentadas pudessem apropriar-se, por meio de informações, e construir reivindicações/demandas voltadas para os direitos sociais e a qualidade de vida nos Assentamentos de Reforma Agrária do município de Nossa Senhora da Glória- SE, por meio dos Conselhos Municipais existentes. Essa apropriação de direitos, atualmente, vem se dando por intermédio dos Conselhos Gestores Municipais. Dessa maneira, o PIBIX (entendido como uma troca de saberes entre a universidade e a sociedade) desempenhou um papel de fornecer subsídios para a participação popular, a partir do tema dos direitos sociais e da qualidade de vida junto aos principais beneficiários da reforma agrária (as famílias assentadas), objetivando que elas pudessem apropriar-se, em algumas situações, ainda mais dos referidos temas mencionados e inspirados no II Plano Nacional da Reforma Agrária (PNRA).

${ }^{7}$ É importante destacar que há controvérsias a respeito da participação do MST em conselhos. De acordo com Débora Goulart (2009, p. 22), "a atuação dos movimentos sociais se configurou na construção de espaços públicos, operando como reconhecimento de representação de interesses e permanente negociação, com vista à ampliação dos direitos coletivos e de uma nova sociabilidade de cunho democrático, porém, o conjunto de proposições neoliberais redefine estes espaços por deslocar da esfera do público, estatal, coletivo, para o mercado o centro das relações sociais, desfigurando o 'bem público'".

${ }^{8}$ Sobre Conselhos populares, enquanto resultado de processos sociais e democráticos, ver: BRETAS; SARAIVA, 2014.

${ }^{9}$ Foi assim que na década de 1990, vários conselhos foram implantados nos diferentes níveis de administração pública (federal, estadual e municipal), em geral com composição paritária entre poder público e sociedade civil; de caráter deliberativo ou consultivo, e na maioria dos casos, sendo condição para o repasse de recursos dos fundos públicos. De tal modo, possibilitam a reorganização das políticas públicas brasileira, por meio de uma maior interação entre o governo e a população, a fim de criar formas de governança democráticas, resultando em políticas sociais de controle social. (GHON, 2003).

${ }^{10}$ No tocante da qualidade de vida, este tema está relacionado aos valores culturais, contextos econômicos e sociais, bem como as percepções apresentadas pela família rural assentada. Na realidade, admite-se que essas famílias possuem concepções e capacidades de elaboração sobre o que representa qualidade de vida, uma vez que a consolidação do assentamento rural, na maioria dos casos, se dá por um árduo período de reivindicação. A qualidade de vida está constituída por elementos específicos ou fatores, os quais formam o contexto da experiência de vida dos indivíduos. (METZEN et al, 1980).

${ }^{11}$ O II- Plano Nacional de Reforma Agrária foi resultado de acúmulos de debates entre técnicos e movimentos sociais, principalmente o MST, na formulação legal de demarcação de terras, em novembro de 2003, durante a Conferência da Terra, em Brasília. Sobre isso, consultar ABRA (2002).

${ }^{12}$ São serviços técnicos prestados aos assentamentos e comunidades rurais, decorrente da Política Nacional de Assistência Técnica e Extensão Rural (PNATER) e o Programa Nacional de Assistência Técnica e Extensão Rural na Agricultura Familiar e na Reforma Agrária (PRONATER).

${ }^{13}$ Vale ressaltar que, o grupo focal apresenta-se de forma pertinente nas ciências humanas, em especial nas ciências sociais, ora por oferecer uma fonte de informação em pesquisas científicas (como assim se sucederam nas décadas de 1970 e 80 em áreas particulares e em processos de pesquisa-ação), ora por ser um rico instrumento técnico nas investigações de pesquisas qualitativas, uma vez que seus resultados produzem-se pela dinâmica interacional de um grupo de pessoas (GATTI, 2005). ${ }^{14}$ Recorri à observação direta para analisar a dinâmica do MST frente a sua participação nos conselhos gestores porque "a observação como técnica de pesquisa não é contemplação beata e passiva; não é também um simples olhar atento. É essencialmente um olhar ativo sustentado por uma questão e por uma hipótese" (LAVILLE; 1999, p. 176).

${ }^{15}$ Consiste essencialmente em elucidar problemas sociais e técnicos, cientificamente relevantes, por intermédio de grupos em que encontram-se reunidos pesquisadores, membros da situação-problema e outros atores e parceiros interessados na resolução dos problemas levantados ou, pelo menos, no avanço a ser dado para que sejam formuladas adequadas respostas sociais, educacionais, técnicas e/ou políticas (THIOLLENT, 2011, p. 7).

${ }^{16}$ Pesquisa participante entendida como "conhecimento coletivo, a partir de um trabalho, que recria, de dentro pra fora, formas concretas dessas gentes, grupos e classes participarem do direito e do poder de pensarem, produzirem e dirigirem os usos de seu saber a respeito de si próprias" (BRANDÃO, 1981, p. 09-10).
} 